\title{
A hydroxyl radical-like species oxidizes cynomolgus monkey artery wall proteins in early diabetic vascular disease
}

\author{
Subramaniam Pennathur, ${ }^{1}$ Janice D. Wagner, ${ }^{2}$ Christiaan Leeuwenburgh, ${ }^{1}$ \\ Kenneth N. Litwak, ${ }^{2}$ and Jay W. Heinecke ${ }^{1,3}$ \\ ${ }^{1}$ Department of Internal Medicine, Washington University School of Medicine, St. Louis, Missouri, USA \\ ${ }^{2}$ Department of Pathology, Wake Forest University School of Medicine, Winston-Salem, North Carolina, USA \\ ${ }^{3}$ Department of Molecular Biology and Pharmacology, Washington University School of Medicine, St. Louis, Missouri, USA
}

Address correspondence to: Jay W. Heinecke, Division of Atherosclerosis, Nutrition and Lipid Research, Box 8046, 660 South Euclid Avenue, St. Louis, Missouri 63110, USA. Fax: (314) 362-0811; E-mail: heinecke@im.wustl.edu.

Christiaan Leeuwenburgh's present address is: Aging Biochemistry Laboratory, University of Florida, Gainesville, Florida, USA.

Kenneth N. Litwak's present address is: Department of Experimental Surgery, University of Pittsburgh, Pittsburgh, Pennsylvania, USA.

Received for publication August 30, 2000, and accepted in revised form January 31, 2001.

Recent evidence argues strongly that the marked increase in risk for atherosclerotic heart disease seen in diabetics cannot be explained by a generalized increase in oxidative stress. Here, we used streptozotocin to induce hyperglycemia in cynomolgus monkeys for 6 months and tested whether high glucose levels promote localized oxidative damage to artery wall proteins. We focused on three potential agents of oxidative damage: hydroxyl radical, tyrosyl radical, and reactive nitrogen species. To determine which pathways operate in vivo, we quantified four stable end products of these reactants - ortho-tyrosine, meta-tyrosine, $o, o^{\prime}$-dityrosine, and 3-nitrotyrosine - in aortic proteins. Levels of ortho-tyrosine, meta-tyrosine, and $o, o^{\prime}$-dityrosine, but not of 3-nitrotyrosine, were significantly higher in aortic tissue of hyperglycemic animals. Of the oxidative agents we tested, only hydroxyl radical mimicked this pattern of oxidized amino acids. Moreover, tissue levels of ortho-tyrosine and meta-tyrosine correlated strongly with serum levels of glycated hemoglobin, a measure of glycemic control. We conclude that short-term hyperglycemia in primates promotes oxidation of artery wall proteins by a species that resembles hydroxyl radical. Our observations suggest that glycoxidation reactions in the arterial microenvironment contribute to early diabetic vascular disease, raising the possibility that antioxidant therapies might interrupt this process.

J. Clin. Invest. 107:853-860 (2001).

\section{Introduction}

Atherosclerotic vascular disease is the leading cause of mortality in the industrialized world, and it develops at an accelerated rate among persons with diabetes mellitus $(1,2)$. However, this greatly increased incidence does not result solely from traditional risk factors, such as obesity, hypertension, and hypercholesterolemia, that frequently are seen in the diabetic population (1, 2). Therefore, there could be a more direct link between diabetes and atherosclerosis. For example, it has long been known that the degree of glycemic control strongly affects the risk for developing many of the disorder's long-term complications. This observation has given rise to the glucose hypothesis, which proposes that hyperglycemia mediates many of the deleterious effects of the disease. This hypothesis has gained strong support from recent clinical trials demonstrating that intensive glucose-lowering therapy dramatically reduces the incidence of microvascular disease (3-5).

Possible links between glucose and vascular disease include mitochondrial dysfunction (6), pseudohypoxia $(7,8)$, altered growth factor and cytokine secretion $(9,10)$, production of advanced glycation end products
(AGE products) $(11,12)$, and increased protein kinase C activity (13). Another important mechanism may involve oxidative stress because a wealth of evidence implicates oxidation of LDL, the major carrier of blood cholesterol, in the pathogenesis of atherosclerosis (14-16). Indeed, glucose promotes protein glycation and AGE product formation in vitro, and AGE products accumulate in tissues of diabetic humans and animals. They also are formed by oxidative reactions in vitro, leading to the proposal that diabetes increases oxidative stress $(11,12,17-25)$.

Recent studies have cast doubt on the concept of a generalized increase in oxidative stress in diabetes, however. For example, Wells-Knecht et al. (26) quantified levels of two oxidized amino acids, ortho-tyrosine and methionine sulfoxide, in collagen isolated from diabetic and nondiabetic subjects. Collagen was chosen for the study because it is an extracellular protein whose slow turnover rate makes it an excellent vehicle for exploring long-term oxidative stress. In vitro studies confirmed that glycoxidation reactions generate the two abnormal amino acids in human collagen, and mass spectrometric analysis of tissue collagen showed 
that levels of both increase linearly with age. However, collagen from age-matched diabetic and euglycemic subjects contained comparable levels of ortho-tyrosine and methionine sulfoxide, which are generated by different reaction pathways in vitro and therefore probably in vivo. Other studies have failed to find differing levels of well-characterized glycoxidation products in urine and blood of diabetic and euglycemic humans $(19,27)$. Collectively, these observations argue strongly against an increase in generalized oxidative stress in diabetes, at least in the extracellular compartment.

A major difficulty in understanding the role of oxidative stress in diabetic macrovascular disease has been the lack of animal models. An important exception is the cynomolgus monkey. In this primate, experimentally induced diabetes enhances atherosclerosis - predominantly fatty streaks and intermediate lesions - in the aorta and femoral arteries $(28,29)$. This effect occurs despite minimal changes in total plasma cholesterol, LDL, HDL, and triglyceride concentrations, and with no increase in AGE products in arterial collagen (28). These monkeys therefore represent an excellent animal model for dissecting out the effects of hyperglycemia alone on oxidative stress in the artery wall.

In the current studies, we used isotope dilution gas chromatography-mass spectrometry (GC/MS), a highly sensitive and specific method, to quantify levels of orthotyrosine, meta-tyrosine, o, 0 '-dityrosine, and 3-nitrotyrosine in proteins isolated from the thoracic aortas of control and diabetic cynomolgus monkeys. In vitro studies have shown that ortho-tyrosine and meta-tyrosine appear when hydroxyl radical oxidizes protein-bound phenylalanine residues. o, o'-Dityrosine is the major product when tyrosyl radical reacts with tyrosine, whereas 3 -nitrotyrosine is generated when peroxynitrite $\left(\mathrm{ONOO}^{-}\right)$oxidizes tyrosine. These abnormal amino acid isomers thus serve as markers, revealing which reactive species have created oxidative damage (16). Our results suggest that even relatively short-term diabetic hyperglycemia promotes protein oxidation in the artery wall in the cynomolgus monkey. The pattern of products suggests that a species resembling hydroxyl radical is the oxidizing intermediate in vivo. These findings support the hypothesis that glucose-induced oxidative stress contributes to the vascular dysfunction and accelerated atherosclerosis of diabetes.

\section{Methods}

Materials. All reagents were obtained from Sigma Chemical Co. (St. Louis, Missouri, USA) or Aldrich Chemical (Milwaukee, Wisconsin, USA) unless otherwise specified. Cambridge Isotope Laboratories (Andover, Massachusetts, USA) supplied ${ }^{13} \mathrm{C}$-labeled amino acids. Isotopically labeled ortho- and meta- $\left[{ }^{13} \mathrm{C}_{6}\right]$ tyrosine, 3-nitro- $\left[{ }^{13} \mathrm{C}_{6}\right]$ tyrosine and $0, o^{\prime}-\left[{ }^{13} \mathrm{C}_{12}\right]$ dityrosine were synthesized as described previously (16). Concentrations of ${ }^{13} \mathrm{C}$-labeled amino acids were determined by HPLC analysis (30).

Animals. The Animal Care and Use Committee of Wake Forest University approved all animal studies.
Sixteen adult male cynomolgus monkeys (Macaca fascicularis) were fed a Western-type diet $(0.28 \mathrm{mg}$ cholesterol/kcal, $45 \%$ of calories from fat) for 2 months before and throughout the 6-month study. The 16 monkeys were randomly assigned to one of two groups, and diabetes was induced in one group by intravenously injecting $30 \mathrm{mg} / \mathrm{kg}$ of streptozotocin (STZ) (28). Plasma lipid and lipoprotein measures and atherosclerosis determinations that included total lesion cholesterol have been reported for these animals previously (28). One animal in the control group died from causes unrelated to the study.

Tissue collection. At the end of the study, the animals were anesthetized with ketamine hydrochloride (15 $\mathrm{mg} / \mathrm{kg}$ given intramuscularly), deeply anesthetized with sodium pentobarbital $(80 \mathrm{mg} / \mathrm{kg}$ given intravenously), and then perfused via the left ventricle with antioxidant solution (lactated Ringer's solution containing $50 \mu \mathrm{M}$ EDTA [a metal chelator], $2.4 \mu \mathrm{M}$ butylated hydroxytoluene [BHT, a lipid-soluble antioxidant], and $0.1 \%$ ethanol [vol/vol]) to prevent ex vivo oxidation. Blood was removed through an incision in the caudal vena cava, and the animals were perfused until the perfusate was colorless. Thoracic aortas were collected from 15 animals (seven controls and eight STZ-treated monkeys) and immediately frozen in liquid $\mathrm{N}_{2}$ in antioxidant solution. Tissues were kept frozen at $-70^{\circ} \mathrm{C}$ until analysis.

Protein isolation. To obtain the in vivo samples, aortic tissue was homogenized at $4{ }^{\circ} \mathrm{C}$ in antioxidant buffer (100 $\mu \mathrm{M}$ diethylenetriaminepentaacetic acid [DTPA], $50 \mu \mathrm{M} \mathrm{BHT}, 1 \%$ [vol/vol] ethanol, and $10 \mathrm{mM} 3$-amino1,2,4-triazole in $50 \mathrm{mM}$ sodium phosphate buffer $[\mathrm{pH}$ 7.4]), frozen briefly, and then thawed. All subsequent procedures were carried out at $4^{\circ} \mathrm{C}$ as described previously (31). Isotopically labeled internal standards were added, and samples were hydrolyzed at $110^{\circ} \mathrm{C}$ for 24 hours under argon (31). Protein for in vitro studies was isolated at $4^{\circ} \mathrm{C}$ from aortic tissue that had been harvested and stored at $-70^{\circ} \mathrm{C}$ in antioxidant solution. Aortic tissue $(-50 \mathrm{mg})$ was homogenized in $5 \mathrm{ml}$ of buffer A (0.1 mM DTPA [pH 7.4]), freeze-thawed once, and centrifuged at $10,000 \mathrm{~g}$ for 10 minutes. The supernatant containing soluble tissue protein was dialyzed against water that had been passed over a Chelex resin (BioRad Laboratories Inc., Hercules, California, USA) column to remove free metal ions. The preparation was stored at $-70^{\circ} \mathrm{C}$.

In vitro protein oxidation by bydroxyl radical, tyrosyl radical, and $\mathrm{ONOO}^{-}$. All reactions (containing $1 \mathrm{mg}$ aortic protein per milliliter) were performed at $37^{\circ} \mathrm{C}$ in buffer $\mathrm{B}$ (50 mM sodium phosphate [pH 7.4]) that had been passed over a Chelex column to remove metal ions. The buffer was supplemented with $5 \mathrm{mM}$ or $15 \mathrm{mM}$ D-glucose. After incubation for 2 hours (hydroxyl radical), 30 minutes (tyrosyl radical), or 5 minutes (ONOO-), reactions were terminated by adding $0.2 \mathrm{mM}$ DTPA ( $\mathrm{pH} 7.4$ ), $300 \mathrm{nM}$ catalase, and $0.1 \mathrm{mM} \mathrm{BHT}$. Hydroxyl radical was generated using buffer $\mathrm{B}$ containing $0.2 \mathrm{mM} \mathrm{CuSO}_{4}$ and 
$5 \mathrm{mM} \mathrm{H}_{2} \mathrm{O}_{2}$. To inhibit residual catalase activity, we included 3-amino-1,2,4-triazole $(0.1 \mathrm{mM})$ in the reaction mixtures. Tyrosyl radical was generated by adding 0.1 $\mathrm{mM} \mathrm{H}_{2} \mathrm{O}_{2}$ to buffer $B$ supplemented with $20 \mathrm{nM}$ myeloperoxidase, $0.2 \mathrm{mM}$ L-tyrosine, and $0.1 \mathrm{mM} \mathrm{DTPA}$. Peroxynitrite was synthesized from 2-ethoxyethyl nitrite and $\mathrm{H}_{2} \mathrm{O}_{2}$ (32) and stored at $-80^{\circ} \mathrm{C}$. Peroxynitrite was thawed immediately before use, and its concentration was determined spectrophotometrically $\left(\varepsilon_{302}=1,670 \mathrm{M}^{-1}\right.$ $\mathrm{cm}^{-1}$; ref. 33). When indicated, buffer B was supplemented with $25 \mathrm{mM} \mathrm{NaHCO}_{3}$ before the addition of $\mathrm{ONOO}^{-}$. For GC/MS analyses, proteins were precipitated with ice-cold trichloroacetic acid (10\% final concentration) and hydrolyzed with acid as described above.

Amino acid derivatization and mass spectrometric analysis. Amino acids were isolated by solid-phase extraction from acid hydrolysates and converted to $n$-propyl heptafluorobutyryl derivatives as described previously (31). The derivatives were quantified by isotope dilution negative-ion chemical ionization GC/MS (16). For phenylalanine, we used the ion at $m / z 383\left(\mathrm{M}^{-}-\mathrm{HF}\right)$ and the isotopically labeled internal standard ion at $\mathrm{m} / \mathrm{z} 389$; for tyrosine, the ion at $m / z 417\left[\mathrm{M}^{-}-\mathrm{CF}_{3}\left(\mathrm{CF}_{2}\right)_{2} \mathrm{CHO}\right]$ and the isotopically labeled internal ion at $m / z 423$; for 3 -nitrotyrosine, the ion at $m / z 464\left(\mathrm{M}^{-}-\mathrm{HF}\right)$ and the isotopically labeled internal standard ion at $\mathrm{m} / \mathrm{z}$ 470; for ortho-tyrosine, the ion at $m / z 595$ ion ( $\left.\mathrm{M}^{-}-\mathrm{HF}\right)$ and the isotopically labeled internal standard ion at $\mathrm{m} / \mathrm{z}$ 601; for meta-tyrosine, the ion at $m / z 417\left(\mathrm{M}^{-}-\mathrm{HF}\right)$ and the isotopically labeled internal standard ion at $\mathrm{m} / \mathrm{z}$ 423; for dityrosine, the ion at $m / z 1208$ ion $\left(\mathrm{M}^{-}-\mathrm{HF}\right)$ and the isotopically labeled internal standard ion at $m / z 1220$. The limit of detection (signal/noise > 10) was less than 1 pmol for all the amino acids.
Statistical analyses. Results are presented as means \pm SE. Differences between two groups were compared using an unpaired Student's $t$ test. Multiple comparisons were performed using a two-way ANOVA. Levels of oxidation products were correlated with those of glycated hemoglobin by linear regression analysis, and the Spearman rank correlation method was applied to nonparametric data using Sigma Stat (SPSS, Chicago, Illinois, USA). A $P$ value less than 0.05 was considered significant.

\section{Results}

To evaluate the potential usefulness of the oxidized amino acids as markers of protein oxidation in vivo, we exposed soluble aortic tissue proteins isolated from nondiabetic cynomolgus monkeys to various oxidation systems in vitro and determined the relative yield of each product. We used the copper-peroxide system to generate hydroxyl radical $\left(0.2 \mathrm{mM} \mathrm{CuSO}_{4}\right.$ and $5 \mathrm{mM}$ $\mathrm{H}_{2} \mathrm{O}_{2}$ ), the myeloperoxidase-tyrosine $-\mathrm{H}_{2} \mathrm{O}_{2}$ system to generate tyrosyl radical $\left(0.1 \mathrm{mM} \mathrm{H} \mathrm{H}_{2} \mathrm{O}_{2}, 20 \mathrm{nM}\right.$ myeloperoxidase, and $0.2 \mathrm{mM}$ tyrosine), and $1 \mathrm{mM}$ $\mathrm{ONOO}^{-}$to generate reactive nitrogen species.

To determine how D-glucose affected the yields of the various oxidation products, we included physiologically relevant concentrations ( $5 \mathrm{mM}$ or $15 \mathrm{mM}$ ) of the sugar in the reaction mixtures. We also determined whether adding $25 \mathrm{mM} \mathrm{NaHCO}_{3}$ to the reaction buffer altered yields of oxidized amino acids in tissue proteins when $\mathrm{ONOO}^{-}$was the reactant. High concentrations of bicarbonate/carbon dioxide are present in vivo, and carbon dioxide reacts rapidly with $\mathrm{ONOO}^{-}$to form $\mathrm{ONO}_{2} \mathrm{CO}_{2}^{-}$, whose reactivity differs from that of $\mathrm{ONOO}^{-}(33,34)$.

ortho-Tyrosine in aortic proteins oxidized in vitro. When we exposed protein derived from aortic tissue to

\section{Figure 1}

Product yields of ortho-tyrosine (a), metatyrosine (b), o, '-dityrosine (c), and 3nitrotyrosine $(\mathbf{d})$ in aortic tissue oxidized by different systems in vitro. Aortic tissue was harvested from nondiabetic animals. Soluble proteins $(1 \mathrm{mg} / \mathrm{ml})$ isolated from this tissue were oxidized in buffer $B$ at $37^{\circ} \mathrm{C}$ with hydroxyl radical, tyrosyl radical, or $\mathrm{ONOO}^{-}$as described in Methods. When indicated, buffer $\mathrm{B}$ was supplemented with $25 \mathrm{mM} \mathrm{NaHCO} 3$ before $\mathrm{ONOO}^{-}$was added (peroxynitrite + $\mathrm{HCO}_{3}{ }^{-}$). D-Glucose was included at the indicated concentrations in the reaction mixtures. After addition of ${ }^{13} \mathrm{C}$-labeled internal standards, proteins were delipidated, hydrolyzed, and subjected to solid-phase extraction. The isolated amino acids were derivatized and analyzed by isotope dilution negative-ion electron capture GC/MS with selected ion monitoring. Values are the mean \pm SEM of triplicate determinations and are normalized to levels of precursor amino acid. ${ }^{A} P<0.01$ by ANOVA.
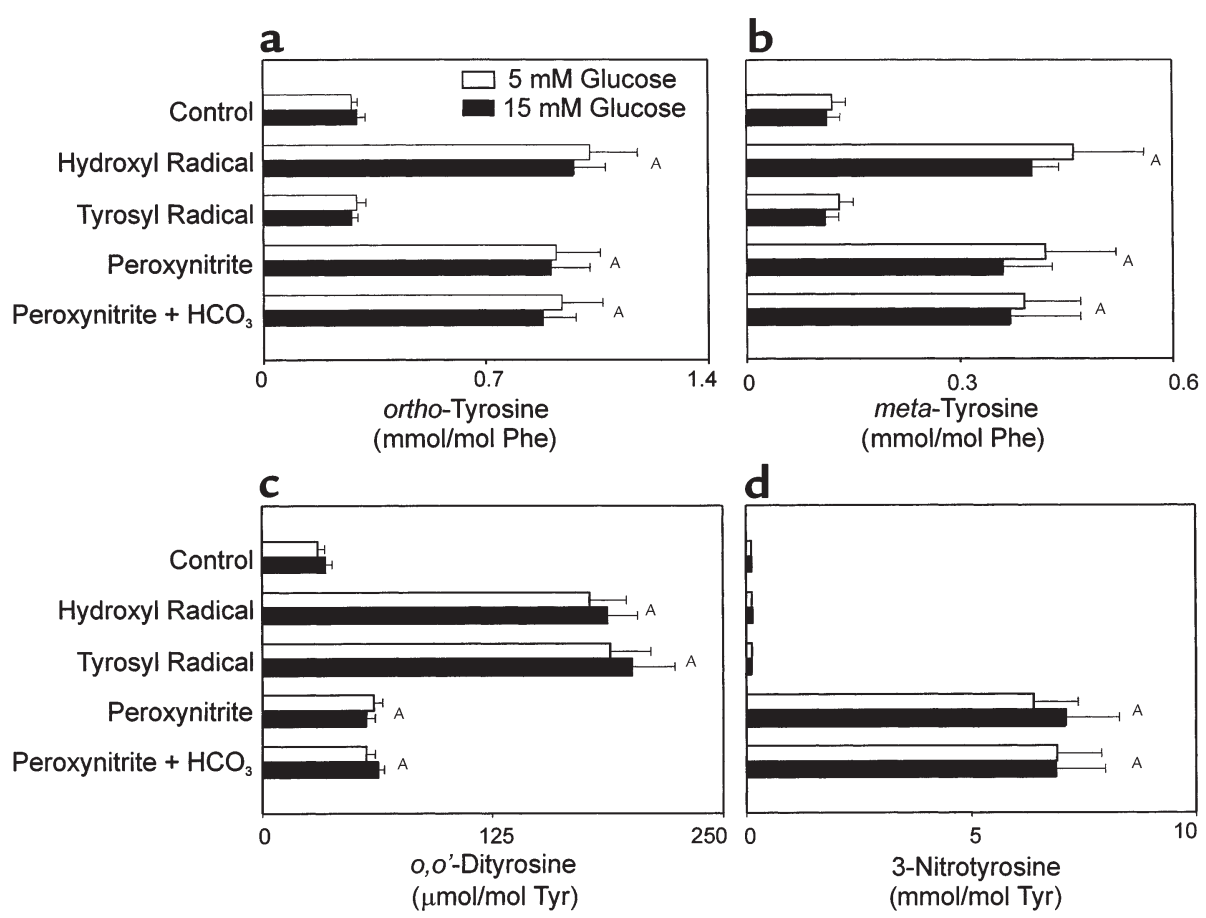

d

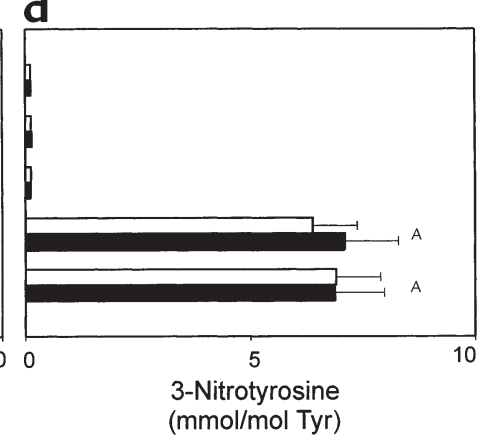




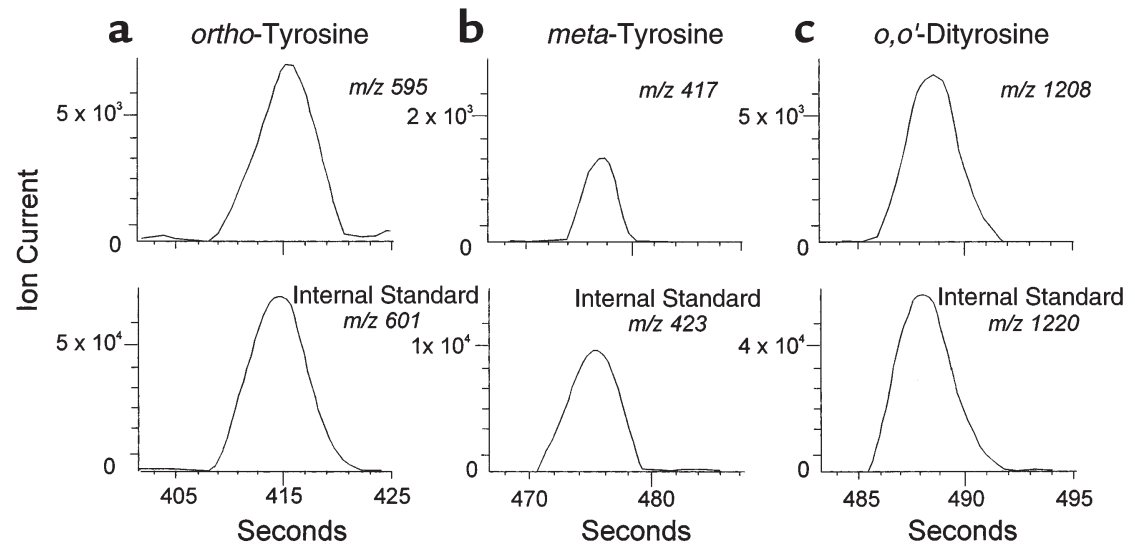

Figure 2

Detection of $n$-propyl heptafluorobutyryl derivatives of ortho-tyrosine (a), meta-tyrosine (b), and $o, o^{\prime}$-dityrosine (c) in monkey thoracic aortic tissue by selected ion monitoring negative-ion electron capture GC/MS. Tissue samples were delipidated, hydrolyzed with acid, and subjected to solid-phase extraction on a C-18 column. Isolated oxidized amino acids were derivatized and analyzed by GC/MS. Note co-elution of the major ion expected for (a) ortho-tyrosine $(\mathrm{m} / \mathrm{z} 595)$ with that of ortho- $\left[{ }^{13} \mathrm{C}_{6}\right]$ tyrosine $(\mathrm{m} / \mathrm{z} 601)$, (b) meta-tyrosine $(\mathrm{m} / \mathrm{z} 417)$ with that of meta- $\left[{ }^{13} \mathrm{C}_{6}\right]$ tyrosine $(\mathrm{m} / \mathrm{z} 423)$, and $(\mathbf{c}) o, o^{\prime}$-dityrosine $(\mathrm{m} / \mathrm{z} 1208)$ with that of $o, o^{\prime}-\left[{ }^{13} \mathrm{C}_{12}\right]$ dityrosine $(\mathrm{m} / \mathrm{z} 1220)$.

hydroxyl radical, the main product was ortho-tyrosine (Figure 1a). Peroxynitrite, but not tyrosyl radical, also generated a significant amount of this abnormal amino acid. Glucose, at a concentration (15 mM) similar to that observed in diabetic humans and monkeys did not affect product yields (Figure 1a). Neither did adding $\mathrm{NaHCO}_{3}$ to the $\mathrm{ONOO}^{-}$system (Figure 1a). These observations suggest that ortho-tyrosine is a major product of oxidation reactions mediated by hydroxyl radical and that it also forms when $\mathrm{ONOO}^{-}$ is the oxidant.

meta-Tyrosine in aortic proteins oxidized in vitro. Hydroxyl radical also generated a high yield of meta-tyrosine (Figure 1b), although $\mathrm{ONOO}^{-}$yielded a significant amount of this amino acid. In contrast, tyrosyl radical failed to raise meta-tyrosine levels. Neither $5 \mathrm{mM}$ nor 15 $\mathrm{mM}$ glucose affected product yields, and $\mathrm{NaHCO}_{3}$ had no effect when added to the $\mathrm{ONOO}^{-}$oxidation system. Elevations in ortho-tyrosine levels always accompanied increases in meta-tyrosine. These observations suggest that both ortho-tyrosine and meta-tyrosine are major products when the hydroxyl radical oxidizes proteins. meta-Tyrosine was also produced when $\mathrm{ONOO}^{-}$was the oxidant. Variations in glucose concentrations over a physiological range did not significantly affect the relative yields of ortho-tyrosine and meta-tyrosine in tissue proteins exposed to hydroxyl radical or $\mathrm{ONOO}^{-}$.

o,o'-Dityrosine in aortic proteins oxidized in vitro. Exposing aortic proteins to oxidizing systems that generate hydroxyl radical or tyrosyl radical raised $0, o^{\prime}$-dityrosine levels, and the two systems produced similar absolute yields (Figure 1c). Peroxynitrite (with or without $\mathrm{NaHCO}_{3}$ ) also increased the level of $0, o^{\prime}$-dityrosine, but the yield was smaller than with hydroxyl radical or tyrosyl radical. Again, glucose (5 mM or $15 \mathrm{mM})$ had no effect.
3-Nitrotyrosine in aortic proteins oxidized in vitro. Exposing aortic proteins to $1 \mathrm{mM}^{\mathrm{ONOO}^{-}}$in vitro greatly raised 3-nitrotyrosine levels ( $\sim 60$-fold). However, protein nitration was minimal when $\mathrm{ONOO}^{-}$was added 2 minutes before the protein (data not shown). This suggests that the nitrating intermediate is either $\mathrm{ONOO}^{-}$itself or a short-lived species derived from it. In contrast, 3-nitrotyrosine levels did not rise when we used the systems that generate tyrosyl radical or hydroxyl radical (Figure 1d). Again, $5 \mathrm{mM}$ or $15 \mathrm{mM}$ glucose failed to affect product yields; $\mathrm{NaHCO}_{3}$ also failed to affect the $\mathrm{ONOO}^{-}$system. These results indicate that 3-nitrotyrosine is the major product when $\mathrm{ONOO}^{-}$oxidizes aortic proteins in vitro.

Diabetes, plasma lipids, and atherosclerosis in cynomolgus monkeys. All eight cynomolgus monkeys injected with STZ developed hyperglycemia, as documented by a significant $160 \%$ increase in glycated hemoglobin (base line, $4.6 \% ; 3$ weeks after STZ, 7.4\%). This high level persisted for the duration of the study (6 months after STZ, 8.3\%). In contrast, glycated hemoglobin levels remained unchanged throughout the study in the seven control animals (base line 4.5\%; 6 months, 3.7\%).

As reported previously (28), there was a trend toward higher plasma cholesterol in the diabetic monkeys than in the control animals after 6 months of hyperglycemia (diabetic $11.1 \pm 1.0 \mathrm{mmol} / 1$, control $8.9 \pm 1.2$ $\mathrm{mmol} / \mathrm{l}$ ), but this difference did not reach statistical significance. Levels of plasma triglycerides, LDL, and HDL did not change. Nevertheless, atherosclerosis became significantly more extensive in the femoral and abdominal aortas of the diabetic animals (28). The thoracic aortas of these animals contained significantly elevated levels of cholesterol (diabetic $12.7 \pm 2.4$ $\mathrm{mg} / \mathrm{g}$; control $6.8 \pm 2.6 \mathrm{mg} / \mathrm{g} ; P<0.05$ ).

Mass spectrometric detection of ortho-tyrosine, meta-tyrosine, 3-nitrotyrosine, and o,o'-dityrosine in cynomolgus monkey aortas. To determine whether the artery wall of nondiabetic monkeys contains oxidized amino acids, we assayed freshly isolated tissue from the thoracic aortas of the control animals. After hydrolyzing the tissue with acid, we derivatized the liberated amino acids with $n$-propanol and heptafluorobutyric anhydride. The derivatives then were analyzed by GC/MS in the negative-ion electron capture mode. Compounds that exhibited major ions and retention times identical to those of authentic orthotyrosine, meta-tyrosine, 3-nitrotyrosine, and $0, o^{\prime}$-dityrosine were detected. Selected ion monitoring demonstrated that the ions derived from the amino acids 

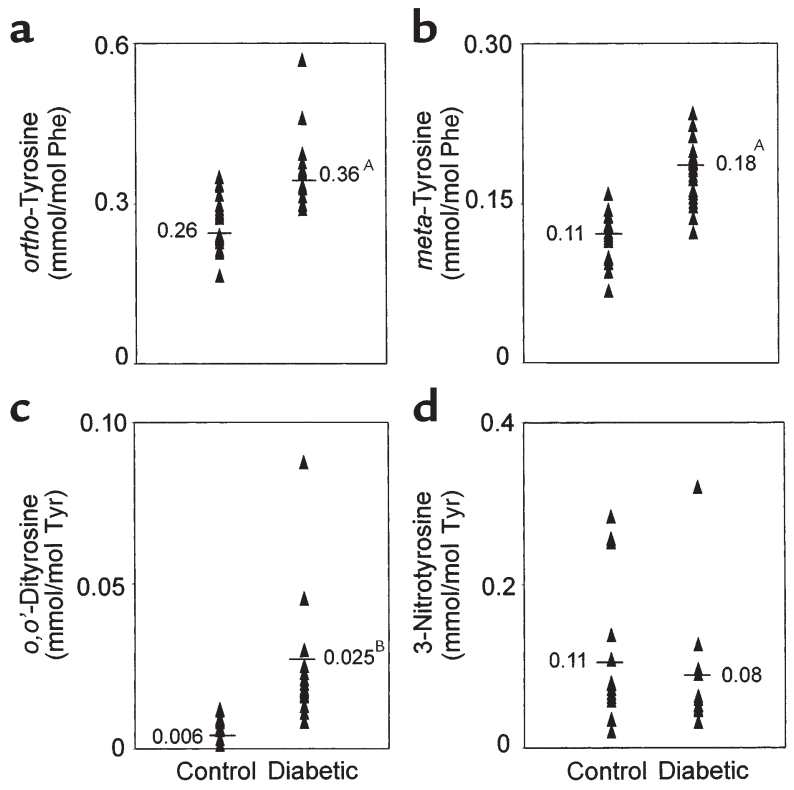

Figure 3

Quantification by isotope dilution GC/MS of (a) ortho-tyrosine, (b) meta-tyrosine, (c) o, o'-dityrosine, and (d) 3-nitrotyrosine in aortic proteins isolated from control and diabetic cynomolgus monkeys. After addition of ${ }^{13} \mathrm{C}$-labeled internal standards, aortic tissue harvested from seven control and eight diabetic animals at the end of the 6-month study was delipidated, hydrolyzed, and subjected to solid-phase extraction. The isolated amino acids were derivatized and analyzed by isotope dilution negative-ion electron capture GC/MS with selected ion monitoring. Tissue samples from three different regions of the aorta from each animal were analyzed. Values are normalized to the precursor amino acids. ${ }^{A} P<0.01$ and ${ }^{B} P<0.005$ by Student's $t$ test.

co-eluted with ions derived from authentic ${ }^{13} \mathrm{C}$-labeled internal standards, as shown in Figure 2 for ortho-tyrosine, meta-tyrosine, and o, $o^{\prime}$-dityrosine.

The aortic samples contained different amounts of the various oxidized amino acids (Figure 3 , a-d). ortho-Tyrosine was the most abundant $(0.2-0.3 \mathrm{mmol} / \mathrm{mol}$ phenylalanine), $0, o^{\prime}$-dityrosine the least ( $<0.1 \mathrm{mmol} / \mathrm{mol}$ tyrosine), and 3-nitrotyrosine and meta-tyrosine were present at intermediate levels $(0.1-0.2 \mathrm{mmol} / \mathrm{mol}$ precursor amino acid). These results indicate that acid hydrolysates of aortic tissue proteins of nondiabetic monkeys contain detectable levels of oxidized amino acids.

Levels of ortho-tyrosine, meta-tyrosine, and o,o'-dityrosine in aortic proteins of diabetic cynomolgus monkeys. To determine whether diabetic hyperglycemia oxidatively damages the artery wall, we analyzed samples from the seven control and eight diabetic cynomolgus monkeys, sampling three different areas from the thoracic aorta of each animal (21 determinations for the control group, 24 for the diabetic group). The aortic proteins from the diabetic animals contained $40 \%$ more ortho-tyrosine than those from the control animals (diabetic, $0.36 \pm 0.01$ $\mathrm{mmol} / \mathrm{mol}$; control, $0.26 \pm 0.01 \mathrm{mmol} / \mathrm{mol}$ phenylalanine; $P<0.01$ ) (Figure $3 \mathrm{a}$ ). When we analyzed the same samples for protein-bound meta-tyrosine (Figure 3b), we detected a $60 \%$ higher level in the diabetic samples than

in the controls (diabetic, $0.18 \pm 0.01 \mathrm{mmol} / \mathrm{mol}$; control, $0.11 \pm 0.01 \mathrm{mmol} / \mathrm{mol}$ phenylalanine; $P<0.01)$. These results indicate that levels of protein-bound ortho-tyrosine and meta-tyrosine are elevated to a similar extent in the artery wall of diabetic animals.

We next analyzed the same tissue for $o, o^{\prime}$-dityrosine (Figure 3c). The concentration in the diabetic samples was fourfold greater than in the control samples (diabetic, $25 \pm 3 \mu \mathrm{mol} / \mathrm{mol}$; control, $6 \pm 1 \mu \mathrm{mol} / \mathrm{mol}$ tyrosine; $P<0.005)$. This indicates that $0, o^{\prime}$-dityrosine levels also are elevated in aortic proteins from diabetic monkeys.

In the diabetic aortic tissue, $0, o^{\prime}$-dityrosine exhibited the largest relative increase $(300 \%)$ but the smallest absolute increase $(0.02 \mathrm{mmol} / \mathrm{mol})$ when compared with ortho-tyrosine and meta-tyrosine. This reflects the marked differences in base-line levels of the oxidized amino acids in tissue. In contrast, ortho-tyrosine showed the greatest absolute increase $(0.10 \mathrm{mmol} / \mathrm{mol})$ but the smallest relative increase (40\%). The absolute increase in tissue levels of meta-tyrosine $(0.07 \mathrm{mmol} / \mathrm{mol})$ was slightly smaller than that of ortho-tyrosine, but it represented a larger relative increase (60\%).

3-Nitrotyrosine levels in aortic proteins of diabetic cynomolgus monkeys. Last, we analyzed the isolated aortic proteins for 3-nitrotyrosine (Figure 3d). There was no significant difference between the diabetic animals and the controls (diabetic, $0.08 \pm 0.02 \mathrm{mmol} / \mathrm{mol}$; control, $0.10 \pm 0.02 \mathrm{mmol} / \mathrm{mol}$ tyrosine). Collectively, these results indicate that levels of ortho-tyrosine, meta-tyrosine, and $o, o^{\prime}$-dityrosine become selectively elevated in aortic proteins of diabetic monkeys, whereas the level of 3-nitrotyrosine remains unchanged.

Correlating levels of the oxidized amino acids with serum levels of glycated hemoglobin. To determine whether hyperglycemia promotes protein oxidation in vivo, we assessed the relationship between glycemic control (measured as

a

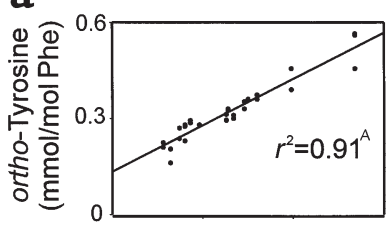

c

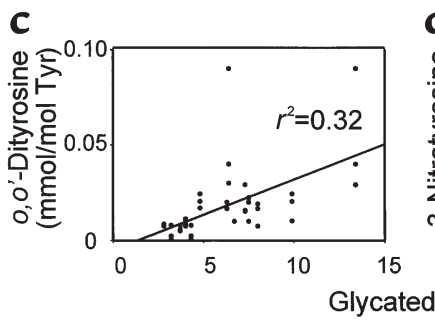

Figure 4

Concentrations of (a) ortho-tyrosine, (b) meta-tyrosine, (c) o,o'-dityrosine, and (d) 3-nitrotyrosine in aortic proteins of cynomolgus monkeys as a function of glycated hemoglobin. Lines represent the linear least squares fit of the data. Glycated hemoglobin was determined in serum of both control and STZ-treated animals at the end of the 6-month study. ${ }^{A} P<0.001$ by Spearman rank correlation. 


\section{Table 1}

Patterns of tyrosine and phenylalanine oxidation products in aortic proteins isolated from diabetic monkeys and in aortic proteins exposed in vitro to hydroxyl radical, peroxynitrite, and tyrosyl radical.

ortho-Tyrosine meta-Tyrosine o,o'-Dityrosine 3-Nitrotyrosine

$\begin{array}{lcccc}\text { Diabetic aortae } & \uparrow & \uparrow & \uparrow & - \\ \text { Hydroxyl radical } & \uparrow & \uparrow & \uparrow & - \\ \text { Peroxynitrite } & \uparrow & \uparrow & \uparrow & \uparrow \uparrow \\ \text { Tyrosyl radical } & - & - & \uparrow & -\end{array}$

$\uparrow$, increased; $\uparrow \uparrow$ markedly increased; - , no change. ${ }^{\mathrm{A}} \pm \mathrm{HCO}_{3}{ }^{-}$.

serum glycated hemoglobin) and levels of amino acid oxidation products in aortic tissue, comparing control and STZ-treated cynomolgus monkeys (Figure 4). Linear regression analysis demonstrated a strong correlation between levels of glycated hemoglobin and levels of both ortho-tyrosine and meta-tyrosine ( $r^{2}=0.9$ and 0.8 , respectively; both $P<0.001)$. There was a borderline significant correlation with levels of $o, 0^{\prime}$-dityrosine $\left(r^{2}=0.3 ; P=0.07\right)$. In contrast, there was no correlation between levels of glycated hemoglobin and those of 3-nitrotyrosine. These observations support the hypothesis that hyperglycemia promotes the formation of ortho-tyrosine and meta-tyrosine in the artery wall and suggest that both glucose and other pathways contribute to $o, o^{\prime}$-dityrosine formation.

We found no correlation between the cholesterol content of thoracic aortic tissue (a measure of atherosclerotic burden) and levels of ortho-tyrosine or meta-tyrosine. There was a weak correlation between levels of $o, o^{\prime}$-dityrosine and tissue cholesterol levels $\left(r^{2}=0.45\right.$; $P<0.05$; data not shown). These observations suggest that differences in the extent of atherosclerosis in euglycemic and hyperglycemic animals are unlikely to account for differing levels of tissue oxidation products.

\section{Discussion}

Although hyperglycemia is widely believed to promote oxidative reactions in vivo, careful quantitative studies have failed to detect elevated levels of ortho-tyrosine and methionine sulfoxide (two oxidized amino acids) in collagen from diabetic humans (26). This observation argues strongly against a generalized increase in oxidative stress in diabetes. In contrast, our observations suggest that hyperglycemia or other components of the diabetic milieu favor oxidative reactions in the microenvironment of the artery wall. Moreover, glucose-stimulated mitochondrial oxidative phosphorylation $(6,35)$ and peroxidation of polyunsaturated fatty acids can generate reactive intermediates in vitro $(19,36,37)$. Therefore, a complex interplay of oxidative reactions involving lipids, carbohydrates, and mitochondria might increase oxidative stress in localized regions of the diabetic artery wall.

We used a highly sensitive and specific method - isotope dilution GC/MS - to investigate pathways that oxidatively damage aortic proteins in normal and diabetic cynomolgus monkeys. Experimentally induced diabetes accelerates atherosclerosis in this animal model as assessed morphologically, biochemically, and histologically (28). When the diabetic animals are compared with euglycemic controls, they show minimal changes in blood cholesterol and triglyceride concentrations, two other important risk factors for vascular disease. Thus, the effects of hyperglycemia on atherosclerosis can be isolated in this primate model. Our cynomolgus experiments revealed that even short-term hyperglycemia elevates levels of ortho-tyrosine, meta-tyrosine, and $0, o^{\prime}$-dityrosine in aortic proteins. Moreover, we uncovered a striking correlation between serum levels of glycated hemoglobin, an index of glycemic control, and aortic tissue levels of both ortho-tyrosine and meta-tyrosine. These observations strongly suggest a link between hyperglycemia and oxidative damage to the artery wall. Thus, hyperglycemia appears to promote the oxidation of protein-bound phenylalanine to ortho-tyrosine and meta-tyrosine early in diabetic macrovascular disease.

The pattern of products we observed in the artery wall proteins strongly resembled the one we obtained by oxidizing isolated artery wall proteins with a system that generates hydroxyl radical (Table 1). This observation raises the possibility that hydroxyl radical or a related intermediate might play an important role in diabetic atherogenesis by creating localized oxidative stress. There was a much lower correlation between tissue levels of $o, o^{\prime}$-dityrosine and glycated hemoglobin, suggesting that pathways independent of glucose contribute to tyrosine oxidation in vivo. One potential mechanism involves the generation of tyrosyl radical by myeloperoxidase or other heme proteins (15).

Our in vitro experiments indicate that physiologically relevant changes in blood glucose are unlikely to affect these oxidative reactions dramatically in vivo. At concentrations $(5 \mathrm{mM}$ and $15 \mathrm{mM})$ that are physiologically relevant to nondiabetic and diabetic monkeys, D-glucose failed to affect the pattern or yields of the oxidation products. We also found that $\mathrm{CO}_{2} / \mathrm{HCO}_{3}{ }^{-}$fails to alter the reactivity of $\mathrm{ONOO}^{-}(33,34)$ : yields of ortho-tyrosine, meta-tyrosine, $o, o$ 'dityrosine, and 3-nitrotyrosine were virtually identical in the presence or absence of added bicarbonate in this system. This likely reflects the presence of residual bicarbonate in tissue and/or buffers. Thus, peroxynitrite-mediated oxidation in vivo is likely to generate a similar pattern of oxidation products to that obtained in vitro.

The pattern of oxidized amino acids that we observed in artery wall proteins implicates a hydroxyl radical-like species in diabetic atherosclerosis. In contrast, we previously have found no elevation of ortho-tyrosine or metatyrosine levels in atherosclerotic human tissue, although we observed a nonsignificant trend toward higher levels of both markers in advanced atherosclerotic lesions (38). Collectively, these observations suggest that hyperglycemia might promote protein oxidation by a biochemical pathway that operates only under features unique to the diabetic artery wall. 
A key question is the mechanism by which hyperglycemia stimulates protein oxidation in arterial tissue. One potential pathway involves mitochondria, which generate reactive species. Many lines of evidence suggest that glucose increases the production of reactive species inside cultured vascular cells $(35,39)$ and that inhibitors of mitochondrial electron transport block this increase (6). Also, in vitro studies have shown that glucose promotes glycoxidation reactions and ortho-tyrosine formation by a pathway that requires redox-active transition metal ions $(19,23)$. Such ions have been detected in tissue homogenates of advanced atherosclerotic lesions $(40,41)$, suggesting that metal-catalyzed oxidation reactions might generate a hydroxyl radical-like species in the microenvironment of the artery wall. AGEs bind metal ions, which might promote additional glucose oxidation and tissue damage (42).

Another potential mechanism for protein oxidation involves $\alpha$-dicarbonyl compounds, which have been implicated in the formation of cross-linked proteins and AGE products in vitro. Studies with model systems demonstrate that Schiff base adducts of methylglyoxal (an $\alpha$-dicarbonyl that increases in diabetes) generate radical cations and superoxide $(43,44)$. These reactions are independent of free metal ions, and they can be executed by protein-bound methylglyoxal, suggesting that this pathway may contribute to oxidative stress in diabetes. However, we have been unable to demonstrate an increase in ortho-tyrosine or meta-tyrosine in model proteins exposed to high concentrations of glucose for prolonged periods - conditions that should promote extensive protein glycation. Instead, we have recently found that glucose and other carbonyl compounds promote protein and lipid oxidation in vitro by a reaction pathway that requires polyunsaturated fatty acids but is apparently independent of free metal ions (S. Pennathur and J.W. Heinecke, unpublished observation). Because atherosclerotic tissue is enriched in polyunsaturated fatty acids, an interplay of glycoxidation reactions involving lipids and carbonyl compounds might promote localized increases in oxidative stress in the microenvironment of the diabetic artery wall.

Diabetes also increases the production of superoxide by vascular tissue (45). Nitric oxide reacts with superoxide at a nearly diffusion-controlled rate to generate $\mathrm{ONOO}^{-}$, a potent oxidant that converts tyrosine into 3 -nitrotyrosine $(33,34)$. Assuming that 3-nitrotyrosine is a specific marker for $\mathrm{ONOO}^{-}$, diabetes might raise aortic levels of this compound. In contrast, in vitro studies have suggested that AGE products scavenge nitric oxide, an event that might impair vasomotor relaxation and lower aortic levels of 3-nitrotyrosine (46, 47). However, we detected no difference in 3-nitrotyrosine levels in diabetic and normal aortic tissues. Moreover, we observed no correlation between tissue levels of 3-nitrotyrosine and levels of glycated hemoglobin, suggesting that hyperglycemia does not directly or indirectly affect the production of reactive nitrogen species in the artery wall. However, there was marked variabil- ity in the extent of protein nitration in both euglycemic and hyperglycemic animals, which may have obscured a biologically significant relationship between the extent of nitration and diabetes. Thus, further studies will be necessary to determine whether hyperglycemia modulates the production of reactive nitrogen species in vascular tissue.

Our detection of increased levels of ortho-tyrosine, meta-tyrosine, and o,o'-dityrosine in diabetic aortic tissue in vivo, together with the characteristic patterns of phenylalanine and tyrosine oxidation products that appear when aortic proteins are oxidized in vitro, suggests that hydroxyl radical or related species oxidizes artery wall proteins. Taken together, these findings raise the possibility that reactive oxidants derived from glucose promote protein oxidation by a pathway unique to the diabetic state. This pathway might be important in the pathogenesis of diabetic vascular dysfunction and atherosclerosis. Therefore, further studies of the biochemical basis for oxidant generation might facilitate the development of specific antioxidant therapies designed to retard diabetic vascular disease.

\section{Acknowledgments}

We thank N. Holmberg for technical assistance and G. Yeh for helpful discussions. Mass spectrometry experiments were performed at the Washington University School of Medicine Mass Spectrometry Resource. This research was supported by grants from NIH (DK02456, AG-15013, DR-56341, AG-13629, DK-56341, RR-00954, HL-63448, and RR-07009). S. Pennathur was the recipient of a Mentor-based Postdoctoral Fellowship from the American Diabetes Association. K.N. Litwak was the recipient of a Postdoctoral Fellowship from the National Center for Research Resources.

1. Semenkovich, C.F., and Heinecke, J.W. 1997. The mystery of diabetes and atherosclerosis: time for a new plot. Diabetes. 46:327-334.

2. Grundy, S.M., et al. 1999. Diabetes and cardiovascular disease: a statement for healthcare professionals from the American Heart Association. Circulation. 100:1132-1133.

3. The DCCT Research Group. 1993. The effect of intensive diabetes treatment on the development and progression of long-term complications in insulin-dependent diabetes mellitus: the Diabetes Control and Complications Trial. N. Engl. J. Med. 329:977-986.

4. UK Prospective Diabetes Study (UKPDS) Group. 1998. Intensive bloodglucose control with sulphonylureas or insulin compared with conventional treatment and risk of complications in patients with type 2 diabetes (UKPDS 33). Lancet. 352:837-853.

5. Nathan, D.M. 1998. Some answers, more controversy, from UKPDS. United Kingdom Prospective Diabetes Study. Lancet. 352:832-833.

6. Nishikawa, T., et al. 2000. Normalizing mitochondrial superoxide production blocks three pathways of hyperglycaemic damage. Nature. 404:787-790.

7. Williamson, J.R., et al. 1993. Hyperglycemic pseudohypoxia and diabetic complications. Diabetes. 42:801-813.

8. Ido, Y., Kilo, C., and Williamson, J.R. 1997. Cytosolic NADH/NAD supply, free radicals and vascular dysfunction in early diabetes mellitus. Diabetologia. 40(Suppl. 2):S115-S117.

9. Pfeiffer, A., and Schatz, H. 1995. Diabetic microvascular complications and growth factors. Exp. Clin. Endocrinol. Diabetes. 103:7-14.

10. Sharma, K., and Ziyadeh, F.N. 1997. Biochemical events and cytokine interactions linking glucose metabolism to the development of diabetic nephropathy. Sem. Nephrol. 17:80-92.

11. Brownlee, M. 1995. Advanced protein glycosylation in diabetes and aging. Annu. Rev. Med. 46:223-234.

12. Bucala, R., and Cerami, A. 1992. Advanced glycosylation: chemistry, biology, and implications for diabetes and aging. Adv. Pharm. 23:1-34. 
13. Ishii, H., Daisuke, K., and King, G.L. 1998. Protein kinase C activation and its role in the development of vascular complications in diabetes mellitus. J. Mol. Med. 76:21-31.

14. Berliner, J.A., and Heinecke, J.W. 1996. The role of oxidized lipoproteins in atherogenesis. Free Rad. Biol. Med. 20:707-727.

15. Heinecke, J.W. 1999. Mass spectrometric quantification of amino acid oxidation products in proteins: insights into pathways that promote LDL oxidation in the human artery wall. FASEBJ. 13:1113-1120.

16. Heinecke, J.W., et al. 1999. Detecting oxidative modification of biomolecules with isotope dilution mass spectrometry: sensitive and quantitative assays for oxidized amino acids in proteins and tissues. Methods Enzymol. 300:124-142.

17. Brownlee, M., Cerami, A., and Vlassara, H. 1988. Advanced glycosylation end-products in tissue and biochemical basis of diabetic complications. N. Engl. J. Med. 232:1315-1321.

18. Bucala, R., Makita, Z., Koschinsky, T., Cerami, A., and Vlassara, H. 1993. Lipid advanced glycosylation: pathway for lipid oxidation in vivo. Proc. Natl. Acad. Sci. USA. 90:6434-6438.

19. Baynes, J.W., and Thorpe, S.R. 1999. Role of oxidative stress in diabetic complications: a new perspective on an old paradigm. Diabetes. 48:1-9.

20. Sell, D.R., and Monnier, V.M. 1989. Structure elucidation of a senescence cross-link from human extracellular matrix: implication of pentoses in the aging process. J. Biol. Chem. 264:21597-21602.

21. Sell, D.R., Lapolla, A., Odetti, P., Fogarty, J., and Monnier, V.M. 1992. Pentosidine formation in skin correlates with the severity of complications in individuals with long-standing IDDM. Diabetes. 41:1286-1292.

22. Wells-Knecht, K.J., Zyzak, D.V., Litchfield, J.E., and Thorpe, S.R. 1995. Mechanism of autoxidative glycosylation: identification of glyoxal and arabinose as intermediates in the autoxidative modification of proteins by glucose. Biochemistry. 34:3702-3709.

23. Wells-Knecht, M.C., Thorpe, S.R., and Baynes, J.W. 1995. Pathways of formation of glycoxidation products during glycation of collagen. Biochemistry. 34:15134-15141.

24. Wolff, S.P., and Dean, R.T. 1987. Glucose autoxidation and protein modification: the potential role of autoxidative glycosylation in diabetes. Biochem. J. 245:243-250.

25. Wolff, S.P., Jiang, Z.Y., and Hunt, J.V. 1991. Protein glycation and oxidative stress in diabetes mellitus and aging. Free Rad. Biol. Med. 10:339-352.

26. Wells-Knecht, M.C., Lyons, T.J., McCance, D.R., Thorpe, S.R., and Baynes, J.W. 1997. Age-dependent accumulation of ortho-tyrosine and methionine sulfoxide in human skin collagen is not increased in diabetes: evidence against a generalized oxidative stress in diabetes. J. Clin. Invest. 100:839-846.

27. Dyer, D.G., et al. 1993. Accumulation of Maillard reaction products in skin collagen in diabetes and aging. J. Clin. Invest. 91:2463-2469.

28. Litwak, K.N., Cefalu, W.T., and Wagner, J.D. 1998. Chronic hyperglycemia increases arterial low-density lipoprotein metabolism and atherosclerosis in cynomolgus monkeys. Metabolism. 47:947-954.

29. Litwak, K.N., Cefalu, W.T., and Wagner, J.D. 1998. Streptozotocininduced diabetes mellitus in cynomolgus monkeys: changes in carbohydrate metabolism, skin glycation, and pancreatic islets. Lab. Anim. Sci. 48:172-178.

30. Hazen, S.L., Hsu, F.F., and Heinecke, J.W. 1996. p-Hydroxyphenylacetaldehyde is the major product of $L$-tyrosine oxidation by activated human phagocytes. A chloride-dependent mechanism for the conversion of free amino acids into reactive aldehydes by myeloperoxidase. J. Biol. Chem 271:1861-1867.
31. Pennathur, S., Jackson-Lewis, V., Przedborski, S., and Heinecke, J.W. 1999. Mass spectrometric quantification of 3-nitrotyrosine, ortho-tyrosine, and o,o'-dityrosine in brain tissue of 1-methyl-4-phenyl-1,2,3, 6-tetrahydropyridine-treated mice, a model of oxidative stress in Parkinson's disease. J. Biol. Chem. 274:34621-34628.

32. Leis, J.R., Pena, M.E., and Rios, A.A. 1993. Novel route to peroxynitrite anion. J. Chem. Soc. Chem. Commun. 16:1298-1299.

33. Lymar, S.V., Jiang, Q., and Hurst, J.K. 1996. Mechanism of carbon dioxide-catalyzed oxidation of tyrosine by peroxynitrite. Biochemistry. 35:7855-7861.

34. Lymar, S.V., and Hurst, J.K. 1996. Carbon dioxide: physiological catalyst for peroxynitrite-mediated cellular damage or cellular protectant? Chem. Res. Toxicol. 9:845-850.

35. Giardino, I., Edelstein, D., and Brownlee, M. 1996. BCL-2 expression or antioxidants prevent hyperglycemia-induced formation of intracellular advanced glycation endproducts in bovine endothelial cells. J. Clin. Invest. 97:1422-1428.

36. Fu, M.X., et al. 1996. The advanced glycation end product, $N$-epsilon-(carboxymethyl)lysine, is a product of both lipid peroxidation and glycoxidation reactions. J. Biol. Chem. 271:9982-9986.

37. Requena, J.R., et al. 1997. Carboxymethylethanolamine: a biomarker of phospholipid modification during the Maillard reaction in vivo. J. Biol. Chem. 272:17473-17479.

38. Leeuwenburgh, C., et al. 1997. Mass spectrometric quantification of markers for protein oxidation by tyrosyl radical, copper, and hydroxyl radical in low density lipoprotein isolated from human atherosclerotic plaques. J. Biol. Chem. 272:3520-3526.

39. Giardino, I., Edelstein, D., and Brownlee, M. 1994. Nonenzymatic glycosylation in vitro and in bovine endothelial cells alters basic fibroblast growth factor activity. A model for intracellular glycosylation in diabetes. J. Clin. Invest. 94:110-117.

40. Lamb, D., Mitchinson, M.J., and Leake, D.S. 1995. Transition metal ions within human atherosclerotic lesions can catalyze the oxidation of low density lipoprotein by macrophages. FEBS Lett. 374:12-16.

41. Swain, J., and Gutteridge, J.M.C. 1995. Prooxidant iron and copper, with ferroxidase and xanthine oxidase activity in human atherosclerotic material. FEBS Lett. 368:513-515.

42. Saxena, A.K., et al. 1999. Protein aging by carboxymethylation of lysines generates sites for divalent metal and redox active copper binding: relevance to diseases of glycoxidative stress. Biochem. Biophys. Res. Commun. 260:332-338

43. Yim, H.S., Kang, S.O., Hah, Y.C., Chock, P.B., and Yim, M.B. 1995. Free radicals generated during the glycation reaction of amino acids by methylglyoxal. J. Biol. Chem. 270:28228-28233.

44. Lee, C., Yim, M.B., Chock, P.B., Yim, H.S., and Kang, S.O. 1998. Oxidation-reduction properties of methylglyoxal-modified protein in relation to free radical generation. J. Biol. Chem. 273:25272-25278.

45. Kojda, G., and Harrison, D. 1999. Interactions between NO and reactive oxygen species: pathophysiological importance in atherosclerosis, hypertension, diabetes and heart failure. Cardiovasc. Res. 15:562-571.

46. Hogan, M., Cerami, A., and Bucala, R. 1992. Advanced glycosylation endproducts block the antiproliferative effect of nitric oxide. Role in the vascular and renal complications of diabetes mellitus. J. Clin. Invest. 90:1110-1115.

47. Vlassara, H., et al. 1992. Exogenous advanced glycosylation end products induce complex vascular dysfunction in normal animals: a model for diabetic and aging complications. Proc. Natl. Acad. Sci. USA. 89:12043-12047. 